\title{
AT4-CS Final Update
}

William C. Moss, Andrew T. Anderson, Ryan M. Vignes

Lawrence Livermore National Laboratory

May 25, 2011 


\begin{abstract}
This document was prepared as an account of work sponsored by an agency of the United States government. Neither the United States government nor Lawrence Livermore National Security, LLC, nor any of their employees makes any warranty, expressed or implied, or assumes any legal liability or responsibility for the accuracy, completeness, or usefulness of any information, apparatus, product, or process disclosed, or represents that its use would not infringe privately owned rights. Reference herein to any specific commercial product, process, or service by trade name, trademark, manufacturer, or otherwise does not necessarily constitute or imply its endorsement, recommendation, or favoring by the United States government or Lawrence Livermore National Security, LLC. The views and opinions of authors expressed herein do not necessarily state or reflect those of the United States government or Lawrence Livermore National Security, LLC, and shall not be used for advertising or product endorsement purposes.
\end{abstract}

This work performed under the auspices of the U.S. Department of Energy by Lawrence Livermore National Laboratory under Contract DE-AC52-07NA27344. 
Project goal is to demonstrate viability of ALE3D for simulating AT4-CS performance

- Primary deliverables are comparisons of experimental and simulated propellant chamber pressure and projectile exit velocity

- Experimental design went through various iterations

- finalized geometry for simulation during mid-April LLNL onsite visit at Benét

- 2D simulation constructed from 3D CAD model and updated data

- JWL igniter/propellant equations-of-state constructed

- Shakedown calculations performed 


\section{Full-view of 2D simulation geometry}

- Simulation details (40K zones, $32 \mathrm{cpu}, 4000 \mathrm{~s} \rightarrow$ simulate to $4 \mathrm{~ms}$

- projectile: $1.96 \mathrm{~kg}$; contains hollow regions

- countermass: $0.9 \mathrm{~kg}$

- cardboard propellant chamber

- Red Dot igniter: 20 gm, 0.875 g/cc

- M38 propellant: 87 gm, 1.096 g/cc

- all non-solid regions filled with air

- slideline along entire length of tube interior including nozzle

- 5 pressure gages

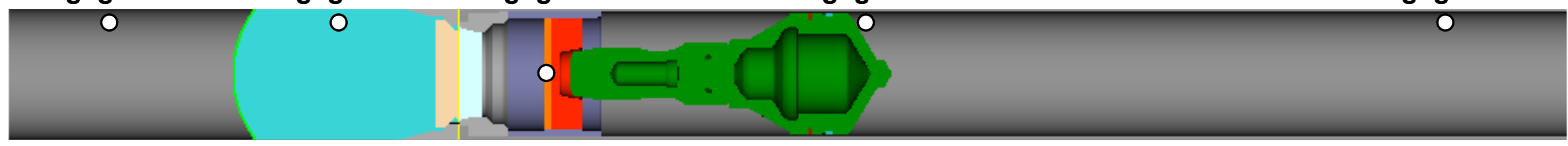




\section{Expanded view of 2D simulation geometry}

- Simulation details

- snap ring and burst disk failure criteria based on time not pressure

- snap ring@750us

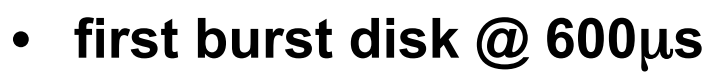

- rear burst disk @ 750us

airspace replaces foam to account for use of denser foam model

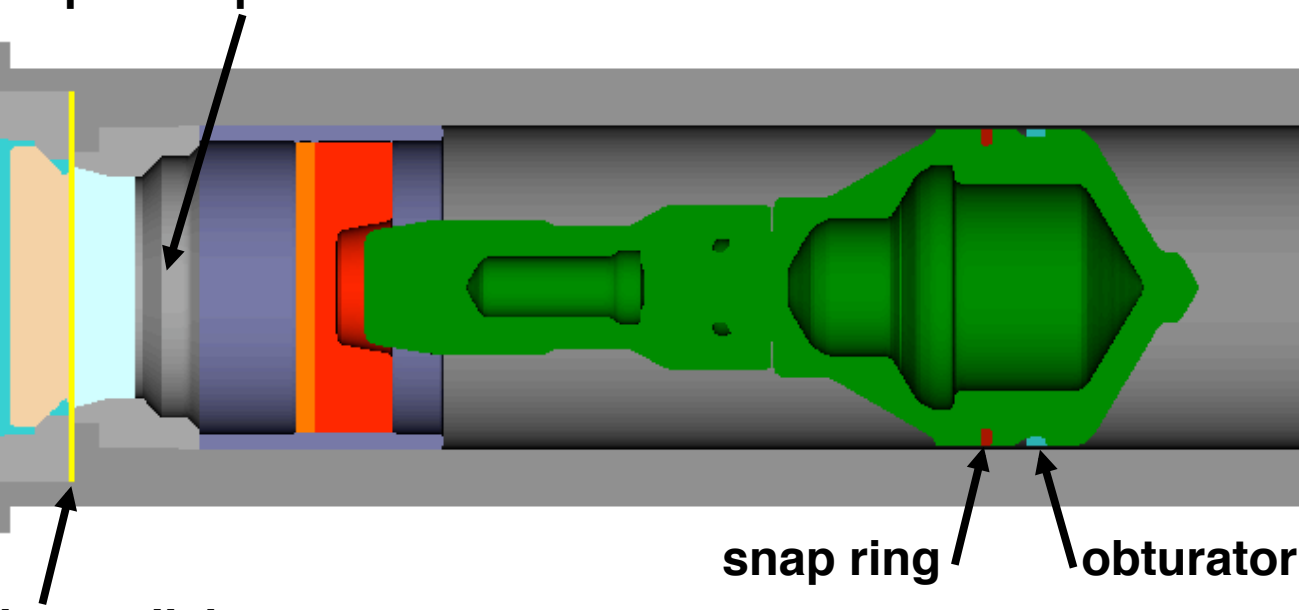




\section{Propellant chamber [deliverable 1 of 2] [gage 3] experiment and simulation}

- Simulation "spikes" before $2 \mathrm{~ms}$ are due to shock reflections resulting from propellant burn model

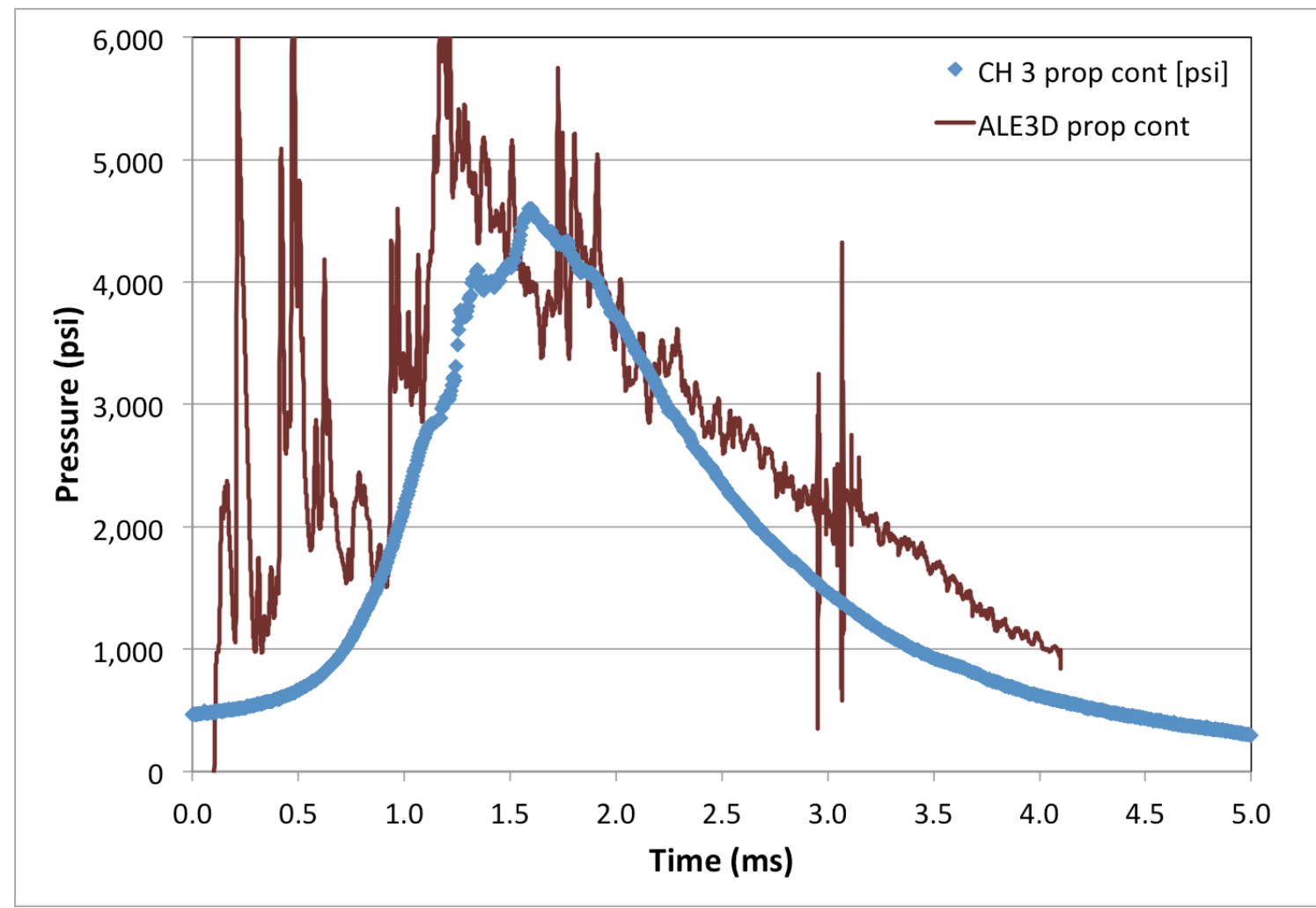

gage 5

gage 4

gage 3

gage 2

gage 1

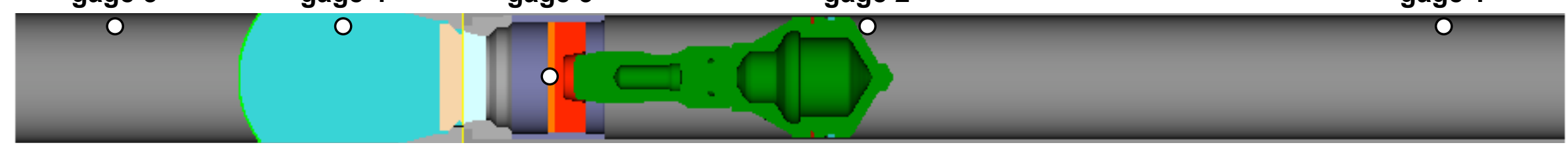




\section{Countermass [gage 4] experiment and simulation}

- Simulation pulsewidth and structure compare favorably with experimental data

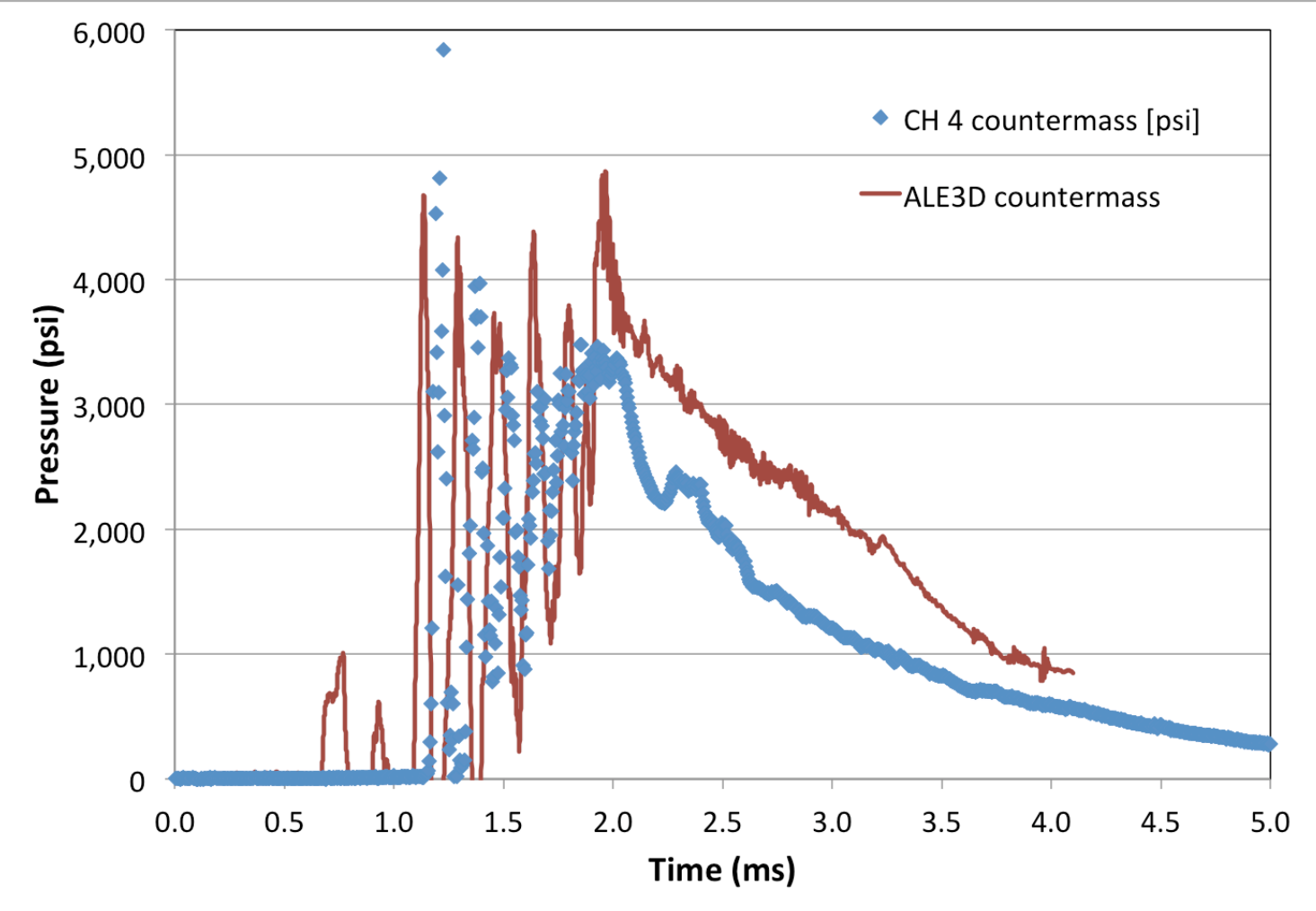




\section{Obturator [gage 2] experiment and simulation}

- Simulation peak and pulsewidth compare favorably with experimental data

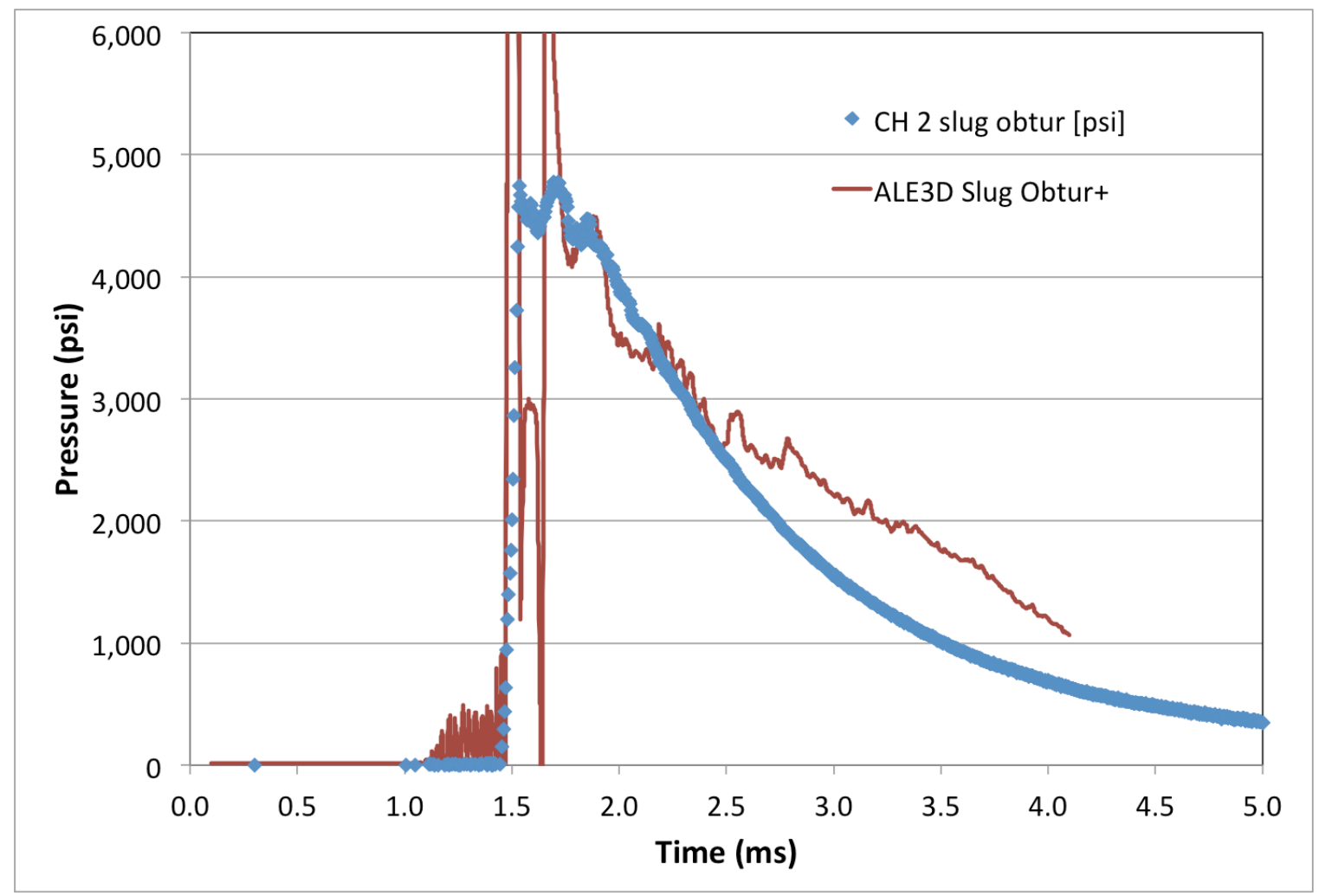

gage 5

gage 4

gage 3

gage 2

gage 1

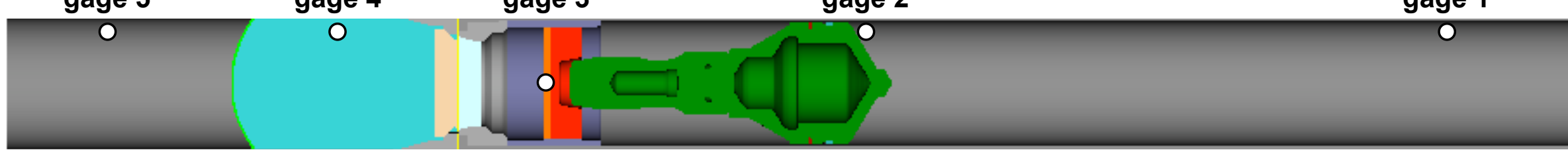




\section{Breech \\ [gage 5] experiment and simulation}

- Simulation peak pressure is too high

- Differences are probably due to details of front burst disk failure, which are beyond the scope of this project

- Consequently, we expect overpredictions at external blast

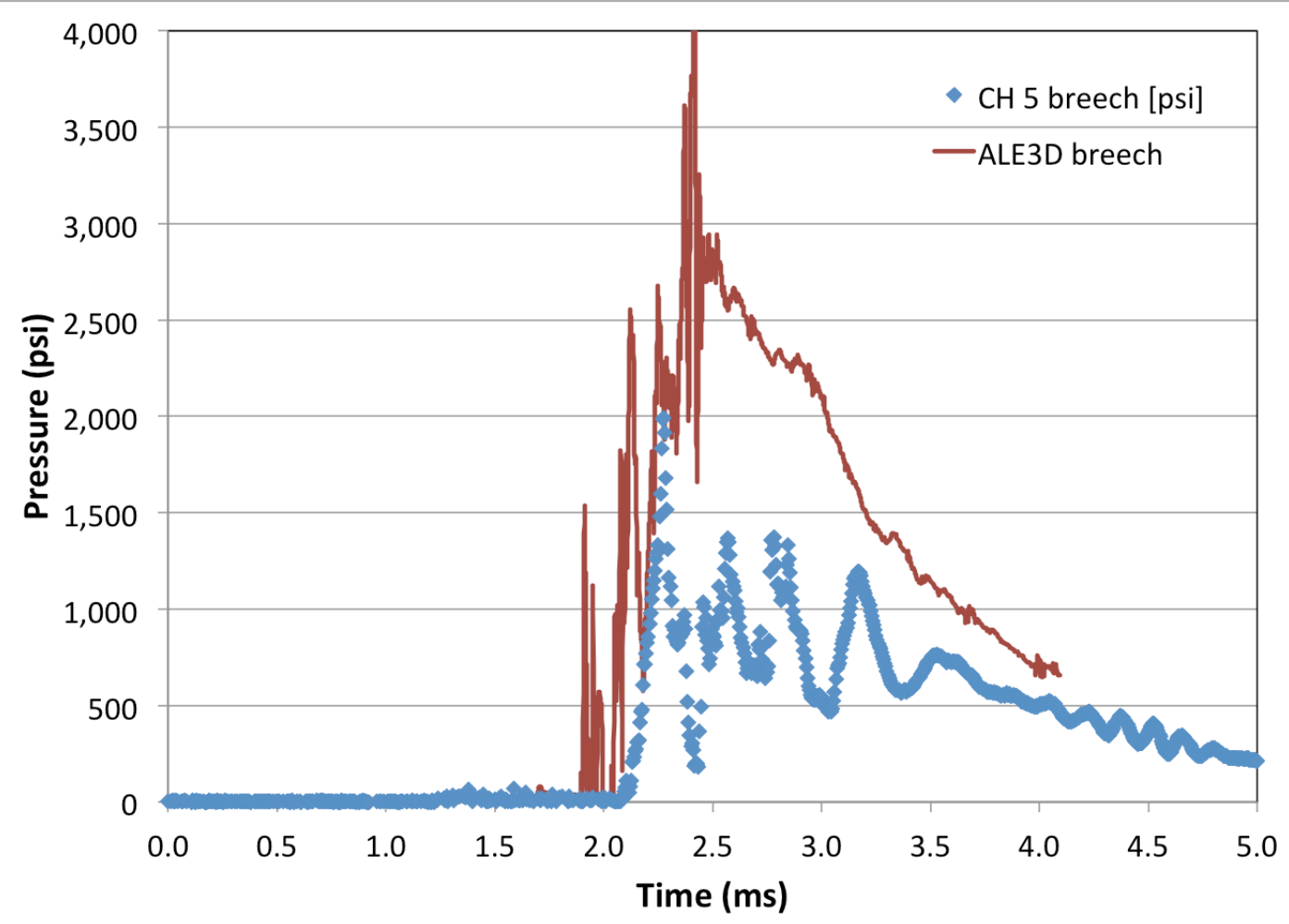

overpressure gages

gage 5

gage 4

gage 3

gage 2

gage 1

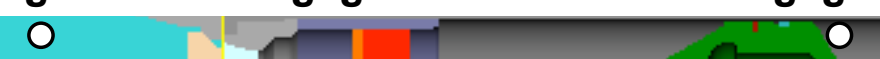




\section{Projectile speed [deliverable 2 of 2] experiment and simulation}

- Simulated exit velocity $(\sim 200 \mathrm{~m} / \mathrm{s})$ compares favorably to $\sim 180 \mathrm{~m} / \mathrm{s}$ experimental velocity

- experimental time-dependent projectile velocity not measured

- experimental projectile exit velocity estimated from data

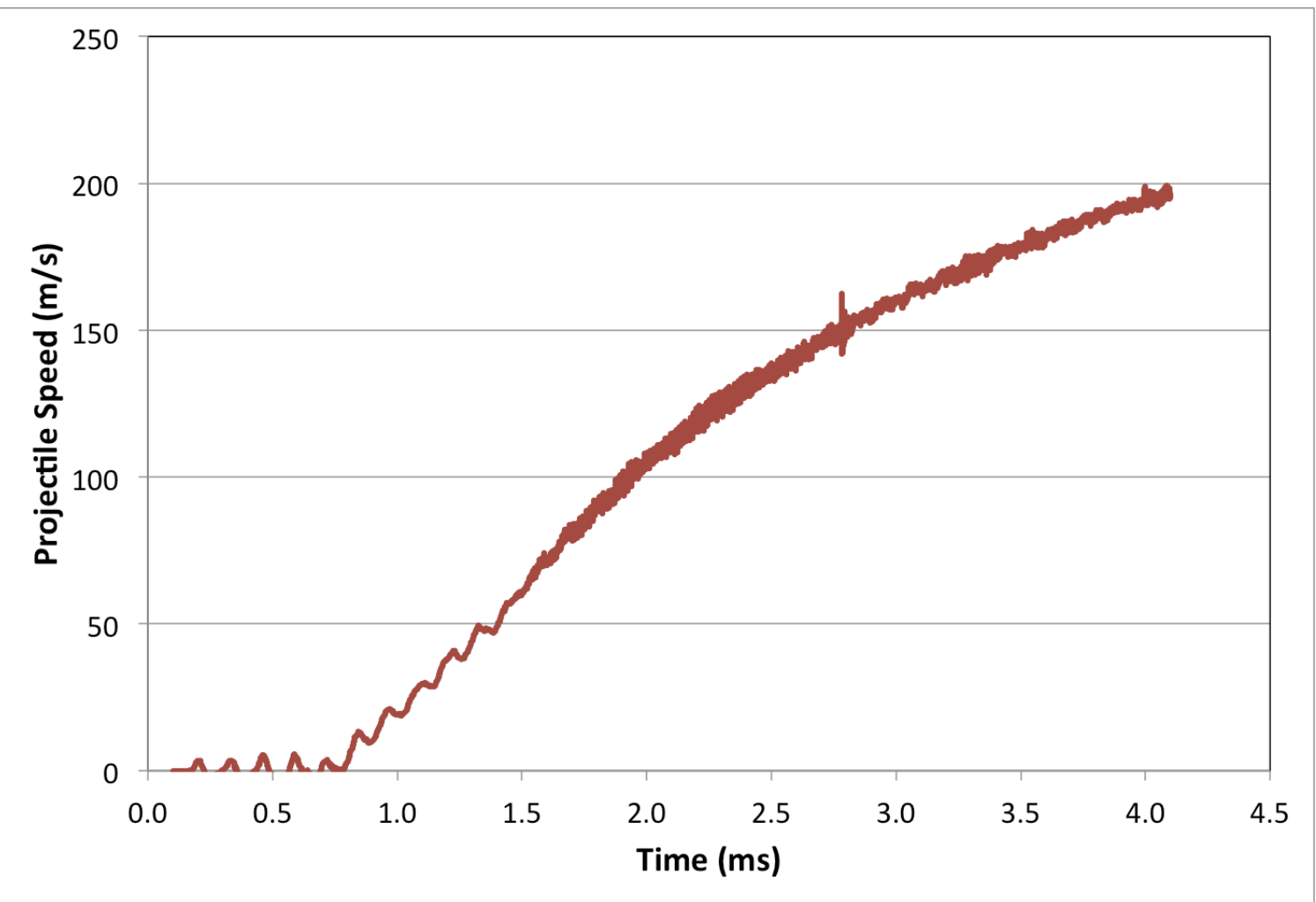


- Simulated projectile speed and propellant chamber pressure agree sufficiently well with data to demonstrate the viability of using ALE3D to simulate the AT4-CS

- Detailed spatial and temporal modeling of the burst disk failure will be required to accurately model the countermass response and subsequent overpressures at Soldier locations around the AT4-CS 